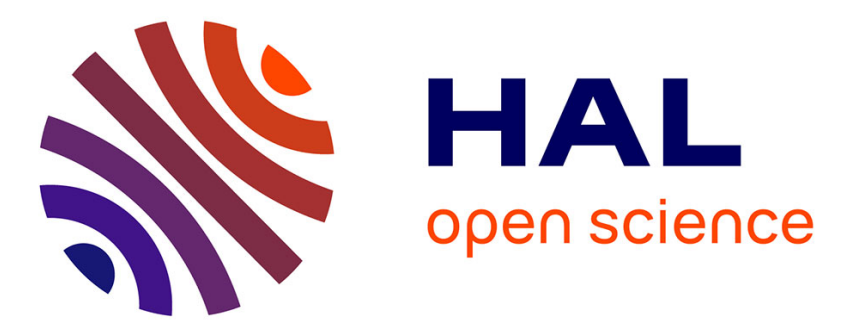

\title{
Macrophage-derived superoxide production and antioxidant response following skeletal muscle injury
}

Emmeran Le Moal, G. Juban, Anne-Sophie Bernard, T. Varga, C. Policar, B. Chazaud, R. Mounier

\section{- To cite this version:}

Emmeran Le Moal, G. Juban, Anne-Sophie Bernard, T. Varga, C. Policar, et al.. Macrophage-derived superoxide production and antioxidant response following skeletal muscle injury. Free Radical Biology and Medicine, 2018, 120, pp.33-40. 10.1016/j.freeradbiomed.2018.02.024 . hal-01783729

HAL Id: hal-01783729

https://hal-univ-rennes1.archives-ouvertes.fr/hal-01783729

Submitted on 3 May 2018

HAL is a multi-disciplinary open access archive for the deposit and dissemination of scientific research documents, whether they are published or not. The documents may come from teaching and research institutions in France or abroad, or from public or private research centers.
L'archive ouverte pluridisciplinaire HAL, est destinée au dépôt et à la diffusion de documents scientifiques de niveau recherche, publiés ou non, émanant des établissements d'enseignement et de recherche français ou étrangers, des laboratoires publics ou privés. 


\section{ACCEPTED MANUSCRIPT \\ MACROPHAGE-DERIVED SUPEROXIDE PRODUCTION AND ANTIOXIDANT \\ RESPONSE FOLLOWING SKELETAL MUSCLE INJURY}

Emmeran Le Moal ${ }^{a, b}$, Gaëtan Juban ${ }^{a, 1}$, Anne Sophie Bernard ${ }^{c}$, Tamas Varga ${ }^{d}$, Clotilde Policar $^{\mathrm{c}}$, Bénédicte Chazaud ${ }^{\mathrm{a}}$, Rémi Mounier ${ }^{\mathrm{a}}$

anstitut NeuroMyoGène, Université Claude Bernard Lyon 1, Univ Lyon, CNRS UMR 5310, INSERM U1217, Lyon, France

${ }^{b}$ Movement Sport and Health Sciences Laboratory, UFR STAPS, Université de Rennes 2, Ecole Normale Supérieure de Rennes, Rennes, France

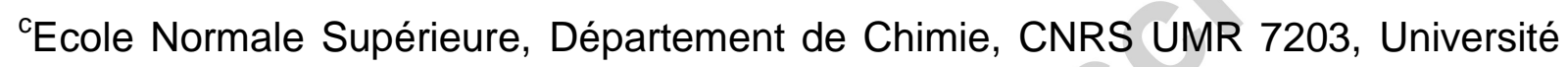
Pierre et Marie Curie, Paris, France

${ }^{\mathrm{d} D e p a r t m e n t}$ of Biochemistry and Molecular Biology, Research Center for Molecular Medicine, University of Debrecen, Debrecen, Hungary

${ }^{1}$ These authors contributed equally

Corresponding author: remi.mounier@univ-lyon1.fr

Institut NeuroMyoGène, Université Claude Bernard Lyon 1, CNRS UMR 5310, INSERM U1217

Faculté de Médecine, 8 Avenue Rockefeller 69008 Lyon

Phone: (33) 426688246 


\section{ACCEPTED MANUSCRIPT}

Running title: Low levels of superoxide in macrophages following skeletal muscle injury

Key words: oxidative stress, tissue repair, sterile inflammation.

Highlights:

- Macrophage-derived ROS release is absent or weak after an acute skeletal muscle injury.

- Antioxidant gene expression is similar in pro and anti-inflammatory macrophages.

- Antioxidant supplementation is deleterious for skeletal muscle regeneration after an acute injury. 


\section{ABSTRACT}

\section{ACCEPTED MANUSCRIPT}

Macrophages are key players of immunity that display different functions according to their activation states. In a regenerative context, pro-inflammatory macrophages $\left(\right.$ Ly6C $\left.^{\text {pos }}\right)$ are involved in the mounting of the inflammatory response whereas antiinflammatory macrophages (Ly6C ${ }^{\text {neg }}$ ) dampen the inflammation and promote tissue repair. Reactive oxygen species (ROS) production is a hallmark of tissue injury and of subsequent inflammation as described in a bacterial challenge context. However, whether macrophages produce ROS following a sterile tissue injury is uncertain. In this study, we used complementary in vitro, ex vivo and in vivo experiments in mouse to show that macrophages do not release ROS following a sterile injury in skeletal muscle. Furthermore, expression profiles of genes involved in the response to oxidative stress in Ly6C $C^{\text {pos }}$ and Ly6C ${ }^{\text {neg }}$ macrophage subsets did not indicate any antioxidant response in this context. Finally, in vivo, pharmacological antioxidant supplementation with $\mathrm{N}$-Acetyl-cysteine (NAC) following skeletal muscle injury did not alter macrophage phenotype during skeletal muscle regeneration. Overall, these results indicate that following a sterile injury, macrophage-derived ROS release is not involved in the regulation of the inflammatory response in the regenerating skeletal muscle. 


\section{INTRODUCTION}

Macrophages play various important roles in tissue homeostasis (Chazaud, 2014). They exhibit a wide spectrum of phenotypes or inflammatory status, which are associated with a diversity of functions (Chazaud, 2014). Upon an immune challenge, macrophages invading the infected area exhibit a pro-inflammatory phenotype, that support microbicidal activity, mainly through the activation of Toll-like receptors (TLRs) upon recognition of Pathogen Associated Molecular Patterns (PAMPs). Once the pathogens phagocytozed and inactivated, resolution of inflammation takes place to avoid too much tissue degradation (Chazaud, 2014). Inflammation is often associated with an increase of the production of reactive oxygen species (ROS) (Le Moal et al., 2017). It is largely accepted that macrophages produce and release ROS to support bactericidal activity and counteract with invader pathogens (West et al., 2011). Thus, ROS are important mediators of macrophage functions during immune challenges (Brune et al., 2013; Forman and Torres, 2001).

After a tissue damage that does not involve bacteria or virus (i.e. sterile inflammation), the activation of macrophages infiltrating the injured area was evidenced via the Damage Associated Molecular Patterns (DAMPs) that also activate TLRs. However, the extent and quality of the pro-inflammatory status of these proinflammatory macrophages have been poorly addressed in vivo. In this context, we recently showed that soon after skeletal muscle injury, monocyte-derived macrophages exhibit a pro-inflammatory status, which is different from that of classical M1 (IFN $\gamma$ driven) activation and is likely related to tissue damage (Varga et al., 2016). Few days after the injury, the resolution of inflammation takes place and macrophages switch their phenotype towards an anti-inflammatory/recovery status to 


\section{ACCEPTED MANUSCRIPT}

exert repairing function in the tissue (Arnold et al., 2007; Mounier et al., 2013; Perdiguero et al., 2011; Varga et al., 2013) .

Whether pro-oxidant characteristics of macrophages that were described in the context of immune challenge does occur in the context of sterile inflammation is still uncertain. iNOS, which participates in the formation of Reactive Nitrogen Species (RNS) and ROS, is expressed by inflammatory macrophages during the first days of muscle regeneration, then its expression declines with time, notably when macrophages acquire the recovery inflammatory status (Mounier et al., 2013). Mice deficient for inos fail to regenerate correctly because of a defect of myogenesis (Rigamonti et al., 2013) suggesting, because inos is mainly expressed by inflammatory macrophages infiltrating the injured area, that macrophage-derived iNOS plays a role in skeletal muscle regeneration. However, despite the assumption that inflammatory macrophages generally produce ROS that are detrimental for the tissue, no study has characterized macrophage ROS production in the context of skeletal muscle regeneration or tissue repair.

The aim of the present study was to evaluate the production of ROS by macrophage populations during skeletal muscle regeneration. To address this question, we combined in vitro and ex vivo approaches of direct biochemical measurements of ROS entities, ex vivo analysis of the "oxidative" gene profile of macrophages isolated from regenerating muscle, and in vivo pharmacological antioxidant supplementation during skeletal muscle regeneration. 


\section{MATERIALS AND METHODS}

\section{Macrophage culture}

Macrophages were obtained from bone marrow (BM) precursor cells as previously described (Mounier et al., 2013). Briefly, total BM was cultured in DMEM (Gibco) containing $20 \%$ fetal bovine serum (FBS) and 30\% conditioned medium of L929 cell line. Macrophages were seeded (200 000 cells $\left./ \mathrm{cm}^{2}\right)$ and activated in DMEM medium containing 10\% FBS for 3 days as follows: IFN- $\gamma(50 \mathrm{ng} / \mathrm{ml}), \mathrm{IL}-4(10 \mathrm{ng} / \mathrm{ml}), \mathrm{IL}-10$ (10 ng/ml), Muscle Damage Associated Molecular Patterns (DAMPS) (homogenate from a muscle injured by ischemia/reperfusion, $1 \mu \mathrm{g} / \mathrm{ml}$ ), lipopolysaccharide (LPS, 10 $\mathrm{ng} / \mathrm{ml}$ ) and Phorbol 12-myristate 13 acetate (PMA, $50 \mathrm{ng} / \mathrm{ml}$ ). After several washes, conditioned medium was obtained after $24 \mathrm{~h}$ of culture of activated macrophages in DMEM serum-free medium.

\section{Superoxide ion production assessment}

Superoxide ion production assessment procedure was previously fully detailed (Bernard et al., 2012). Ferricytochrome $c$ reduction was used to assess the superoxide ion production by macrophages. Macrophages activated as described above were incubated at $37^{\circ} \mathrm{C}$ for $2 \mathrm{~h}$ with $1 \mathrm{ml}$ of HEPES buffer (53 mM HEPES) $\mathrm{pH}$ 7.4 containing $14.6 \mathrm{mM}$ glucose, $358 \mathrm{mM} \mathrm{NaCl}, 12.7 \mathrm{mM} \mathrm{KCl}, 3.1 \mathrm{mM} \mathrm{KH}_{2} \mathrm{PO}_{4}, 6.1$ $\mathrm{mM} \mathrm{MgSO} 4,3.1 \mathrm{mM} \mathrm{CaCl}_{2}, 13 \mathrm{mM} \mathrm{NaHCO} 3,0.4 \mathrm{mM}$ EDTA and $100 \mu \mathrm{M}$ ferricytochrome. Absorbance was read at $550 \mathrm{~nm}$ with a spectrophotometer (BioSpectrometer Basic Eppendorf). Contribution of ferricytochrome $c$ at $100 \mu \mathrm{M}$ (absorbance at $800 \mathrm{~nm}$ ) was substracted. Similar measurements were realized on macrophages isolated by FACs (see below) and subsequently plated for $2 \mathrm{~h}$ in the absence or presence of PMA (50 ng/ml) to induce an oxidative burst (Abbas et al., 2014). 


\section{ACCEPTED MANUSCRIPT}

\section{Superoxide dismutase expression}

Protein concentration was determined in macrophage lysates using BCA protein assay (Uptima-Interchim). Western blot analysis was performed to examine the expression of MnSOD (rabbit polyclonal anti-human SOD2 $200 \mu \mathrm{g} / \mathrm{ml}$, Santa Cruz Biotechnology) and Cu-ZnSOD (rabbit polyclonal anti-human SOD1 $200 \mu \mathrm{g} / \mathrm{ml}$, Santa Cruz Biotechnology) versus that of actin (Goat polyclonal anti-human actin 200 $\mu \mathrm{g} / \mathrm{ml}$, Santa Cruz Biotechnology). Quantification of the band intensity was performed using ImageJ Software.

\section{Macrophage $\mathrm{H}_{2} \mathrm{O}_{2}$ release}

Extracellular $\mathrm{H}_{2} \mathrm{O}_{2}$ was detected using the Amplex Red hydrogen peroxide/peroxidase assay kit (Invitrogen). Macrophage-conditioned medium was collected and incubated with the Amplex Red reagent ( $50 \mu \mathrm{l}$ of $10 \mathrm{mM}$ solution) and horseradish peroxidase $(100 \mu \mathrm{l}$ of $10 \mathrm{U} / \mathrm{ml}$ solution) in $0.25 \mathrm{M}$ sodium phosphate buffer for $30 \mathrm{~min}$. Absorbance intensity was measured on an Apollo LB 911 plate reader (Berthold Technologies) at $560 \mathrm{~nm}$.

\section{Skeletal muscle injury}

Eight week-old $\mathrm{C} 57 / \mathrm{BI} 6$ and $\mathrm{CX} 3 \mathrm{CR} 1^{\mathrm{GFP} /+}$ male mice were used for $\mathrm{N}$-acetylcysteine (NAC, Sigma) supplementation protocol and extraction of macrophages from regenerating muscle, respectively. Mice were bred and used in compliance with French and European regulations. Principal investigators are licensed for animal experimentation and the ethical committee validated the protocol. Muscle injury was caused by injection of cardiotoxin (CTX) in the Tibialis Anterior muscle as previously described (Mounier et al., 2013). In some experiments, LPS (50 $\mu \mathrm{g} / \mathrm{ml}$ final) was coinjected with CTX as previously described (Varga et al., 2016). In some experiments, 


\section{ACCEPTED MANUSCRIPT}

NAC was administered at $4 \%$ in drinking water for 8 days from the day of injury, as previously described (Terrill et al., 2012).

\section{Isolation of immune cells from regenerating muscle}

Immune cells were isolated as described previously (Mounier et al., 2013; Varga et al., 2016). Briefly, muscles were minced and digested with collagenase B $0.2 \%$. $\mathrm{CD}_{4} 5^{+}$cells were isolated by magnetic sorting procedure (Miltenyi Biotec) and further labeled with APC-CD64 and PE-Ly6C antibodies for C57/BI6 mice and with an APCLy6C (all from eBiosciences) antibody for CX3CR $1^{\mathrm{GFP} /+}$ mice. Cells were sorted using a FACS Aria II cell sorter (BD Biosciences).

\section{Histological analysis}

At different time-points after injury (day 4, 8 and 28) regenerating muscles were harvested, snap-frozen in nitrogen-chilled isopentane and kept at $-80^{\circ} \mathrm{C}$ until analysis. $10 \mu \mathrm{m}$-thick muscle cryosections were prepared and used for $\mathrm{H} / \mathrm{E}$ staining and immunofluorescent staining. Cryosections were treated with antibodies directed against F4/80 (\#ab6640, Abcam), iNOS (\#ab15323, Abcam), and CD206 (\#sc-58987,

Santa Cruz) revealed with FITC-or Cy3-conjugated antibodies (Jackson Immunoresearch Inc). Pictures were recorded with Axioscop microscope (Zeiss) at 20X of magnification connected to AxioCam ICc5 (Zeiss). For each condition in each experiment, at least 8-10 randomly chosen fields were counted. The number of labeled macrophages was calculated using ImageJ software and was expressed as a percentage of total macrophages.

For Cross Section Area (CSA) analysis, cryosections were labeled with antibodies directed against Laminin (\#L9393, Sigma-Aldrich) and revealed with FITC-conjugated secondary antibody. Pictures covering the whole cryosection were recorded with an Axio Observer.Z1 (Zeiss) at 10X of magnification connected to a CoolSNAP HQ2 


\section{ACCEPTED MANUSCRIPT}

CCD Camera (Photometrics). CSA was determined manually using ImageJ software. A mean of $2345+/-542$ fibers were analyzed per TA muscle.

For satellite cells analysis, fresh cryosections were labeled with antibodies directed against Pax7 (clone 4ea, DHSB) and Laminin (\#L9393, Sigma-Aldrich) revealed with Cy3- and FITC-conjugated antibodies, respectively. Pictures were recorded with an Axio Imager.Z1 (Zeiss) at 20X of magnification connected to a CooISNAP Myo CCD Camera (Photometrics). For each condition, 10 randomly chosen fields were counted. The number of satellite cells was determined manually using ImageJ software and expressed as the number of Pax7+ cells per 100 fibers.

\section{Statistical analyses}

Results are expressed as means \pm SEM. All experiments were carried out with at least 3 different primary cultures or 3 mice for in vivo analyses. Isolation of macrophages from regenerating muscle required 3 to 5 mice that were pooled. Mann- Whitney and Kruskal-Wallis tests were done with Prism software. 


\section{RESULTS}

\section{Pro- and anti-inflammatory macrophages release similar levels of ROS in vitro}

To investigate ROS production by differentially activated macrophages, BM-derived macrophages were treated with a (IFN- $\gamma)$, with IL-4 or with IL-10 to trigger proinflammatory, alternative and anti-inflammatory activation, respectively (Murray et al., 2014). Superoxide production in conditioned medium was assessed using ferricytochrome $c$ reduction assay (Bernard et al., 2012). This method, based on the reduction of cytochrome $\mathrm{c}$ by superoxide to form detectable ferrocytochrome, reflects the extracellular production of superoxide. No significative superoxide production was observed upon the 3 treatments, despite a slight increase by macrophages activated with IFN $\gamma$ (Figure 1A). To investigate ROS production by pro-inflammatory macrophages in vitro, cells were treated with various effectors known to induce proinflammatory states including a ROS-inducer (PMA), a bacterial mimetic (LPS) and a lysate from injured skeletal muscle (DAMPS). Because the measurement of anion superoxide release has never been performed in these conditions, we added two positive controls known as superoxide generators: a strong chemical inducer (PMA) (Nathan and Root, 1977) and LPS. LPS activates superoxide production and hydrogen peroxide-derived superoxide. We also tested DAMPS as a putative superoxide activator. Hence, we validated our measurement setup and were able to underline the differences between classical models of activation based on cytokine treatment and the above-mentioned treatments. Among the 3 treatments, only PMA $(+139 \pm 9 \%) \quad(p<0.05)$ treatment induced superoxide detection as compared with untreated macrophages (NT) (Figure 1A). To further explore ROS metabolism in activated macrophages, the level of $\mathrm{H}_{2} \mathrm{O}_{2}$, which is the product of superoxide dismutation by superoxide dismutases (SODs) (Holmstrom and Finkel, 2014), was 


\section{ACCEPTED MANUSCRIPT}

measured in conditioned media. Surprisingly, hydrogen peroxide production was similar in all macrophage populations (Figure 1B). The important lability of $\mathrm{H}_{2} \mathrm{O}_{2}$ can explain these results. Overall, these data indicate that macrophages released similar levels of superoxide and $\mathrm{H}_{2} \mathrm{O}_{2}$ irrespective of their activation state.

We further examined the expression of superoxide dismutase (SOD) enzymes by activated macrophages. MnSOD (or SOD2) is a mitochondrial enzyme responsible of the dismutation of primary formed superoxide into hydrogen peroxide, the most common reaction of ROS metabolism cascade (Holmstrom and Finkel, 2014). MnSOD expression was higher in IFN $\gamma$ macrophages as compared with (IL-10) macrophages $(p<0.05)$ (Figure 1C). Additionally, cytosolic SOD1 (or CuZn-SOD) expression was not significantly different in the various activated macrophages (Figure 1D). These data indicate that mitochondrial SOD2 was overexpressed only in pro-inflammatory macrophages, leading to an improvement of the dismutation capacity of pro-inflammatory macrophages that may result in a similar ROS release as compared with other activated macrophages.

\section{Macrophages produce low levels of superoxide during post-injury skeletal muscle regeneration in vivo}

To investigate ROS production by macrophages during muscle regeneration, macrophages subsets and neutrophils were sorted from regenerating muscle at day 2 after injury and assayed for the evaluation of superoxide production (Figure 2A). At day 2, both LyC6 $^{\text {pos }}$ and Ly6C ${ }^{\text {neg }}$ populations are equally present (Mounier et al., 2013; Varga et al., 2013). No significant superoxide production was detected in both Ly6C ${ }^{\text {pos }}$ and Ly6C $C^{\text {neg }}$ macrophage subsets and neutrophils, as compared with the control solution (Figure 2A, right panel). To test the experimental conditions and the 


\section{ACCEPTED MANUSCRIPT}

ability of myeloid cells isolated from regenerating muscles to produce superoxide, sorted macrophages and neutrophils were immediately treated with PMA, which induces an oxidative burst and is widely used to study ROS production in myeloid cells. In this condition, PMA-stimulated neutrophils significantly produced ROS, with an upregulation of superoxide release of $162.6 \pm 9.4 \%(p<0.001)$ (Figure 2A, right panel).

Additionally, a skeletal muscle injury model with concomitant bacterial contamination with LPS was used to induce a stronger pro-inflammatory profile of Ly6C macrophages (Varga et al., 2016) (Figure 2B, left panel). No significant superoxide production was detected in both macrophage subsets and neutrophils, as compared with the control solution (Figure 2B, right panel). Again, treatment with PMA stimulated only neutrophils to produce superoxide $(144.1 \pm 13.2 \%, p<0.05)$ (Figure 2B, right panel). Taken together, these results indicate that after an injury, macrophages invading skeletal muscle release, if any, very low levels of superoxide.

Gene expression profiling does not reveal antioxidant-related response in macrophages after skeletal muscle injury

The oxidative stress signature of macrophages present in regenerating muscles was investigated, using a microarray analysis published in (Varga et al., 2016). As expected, Ly6C ${ }^{\text {pos }}$ macrophages expressed higher levels of a series of genes known to be associated with pro-inflammatory macrophages in skeletal muscle regeneration, including selectin L, CSF1, IL6 and CCR1 (Figure 3, upper panel). A set of antioxidant genes that would identify an antioxidant-related transcriptional signature was analyzed in both macrophage subsets. There was no significant differential expression of 30 genes associated with response to oxidative stress 


\section{ACCEPTED MANUSCRIPT}

between inflammatory Ly6C ${ }^{\text {pos }}$ and restorative Ly6C $C^{\text {neg }}$ macrophage subsets (Figure

\section{3, lower panel).}

\section{NAC treatment impairs skeletal muscle regeneration after injury}

To further assess a potential functional role of ROS in macrophages during skeletal muscle regeneration, we used a pharmacological approach using antioxidant NAC oral treatment, given from the time of muscle injury. Indeed, NAC should counteract the ROS released at early time points by pro-inflammatory macrophages. Inversely, if no ROS are present in the injured muscle, NAC should not affect skeletal muscle regeneration.

First, macrophage inflammatory status was investigated by performing double immunofluorescent staining for $\mathrm{F} 4 / 80$ and iNOS or CD206, to identify pro- and antiinflammatory macrophages, respectively (Mounier et al., 2013). At day 4 after injury, there was no difference in the percentage of macrophages expressing iNOS or CD206 between control and NAC-treated muscles (Figure 4A). The number of necrotic and phagocyted myofibers was calculated 8 days after injury, a time point when most of necrosis and phagocytosis of injured myofibers is over (Mounier et al., 2013). Although exhibiting high variations between individuals, NAC-treated group did not significantly differ from the control group (Figure 4B), indicating no significant difference in the time course of the regeneration process. Four weeks after injury, NAC treatment was associated with a reduction of body weight $(-9 \%, \mathrm{p}<0.01)$, Tibialis Anterior muscle mass $(-15 \%, \mathrm{p}<0.001)$ and Tibialis Anterior mass/body mass ratio $(-8 \%, p<0.05)$ (Figure 5B). This was correlated with a decrease in mean Cross Section Area $(-15 \%, p<0.05)$ and a shift of the myofiber size towards the smaller ones (Figure 5C). Additionally, muscles from NAC-treated group displayed a 


\section{ACCEPTED MANUSCRIPT}

significant lower number of nuclei per fiber as compared with the control group ($22 \%, p<0.001$ ) (Figure 5D). Finally, NAC-treated muscles did not show a significant difference in the number of satellite cells (Figure 5E). Altogether, these results suggest that NAC treatment primarily affected myofiber growth than early events related to inflammation during skeletal muscle regeneration. 


\section{ACCEPTED MANUSCRIPT}

\section{DISCUSSION}

We investigated ROS release from macrophages during regenerating skeletal muscle and provided evidence that after a sterile injury, infiltrated macrophages did not release ROS and that antioxidant supplementation impaired long term skeletal muscle regeneration. To our knowledge, only one study investigated whole skeletal muscle redox changes following skeletal muscle injury induced by venom injection. It was described that skeletal muscle injury is accompanied by an increase of ROS production within the whole tissue from 1 to 7 days after injury (Vezzoli et al., 2011). However, the pro/antioxidant-related measurements were not specific to macrophage populations. These results, combined to those of the present study, suggest that ROS present in the early injured muscle are mainly derived from the myofiber than from the inflammatory compartment.

ROS are short lived and direct detection is difficult, notably in vivo, despite recent technological advances (Murphy et al., 2011; Winterbourn, 2008). Here, we used biochemical assays such as ferricytochrome $c$ reduction and Amplex Red technology, which are robust, specific and adequate methods to detect the major ROS that are superoxide and hydrogen peroxide produced by the cells and released in their microenvironment (Bernard et al., 2012; Wang et al., 2012).

We report that among a set of in vitro activation, only macrophages treated with PMA, which induces the oxidative burst in macrophages (Abbas et al., 2014), present a significant ROS production. Additionally, no difference was observed in the release of $\mathrm{H}_{2} \mathrm{O}_{2}$, which is the product of superoxide dismutation, between the different activated macrophage populations. Protein expression of MnSOD, responsible of the dismutation of superoxide into hydrogen peroxide, the most common reaction of ROS metabolism cascade at this step (Holmstrom and Finkel, 2014), is higher in IFN $\gamma$ 


\section{ACCEPTED MANUSCRIPT}

treated macrophages as compared with other activated macrophages. This distinct pattern of MnSOD is a hallmark of IFN $\gamma$-activated macrophages (Lawrence and Natoli, 2011). This result indicates that a higher MnSOD protein expression may counteract a higher production of superoxide (not detectable in our experimental conditions) as a stress response to restore cellular homeostasis.

Ex vivo isolation of pure populations of pro-inflammatory and anti-inflammatory macrophages (Ly6C ${ }^{\text {pos }}$ and $L y 6 C^{\text {neg }}$, respectively) two days after muscle injury revealed no significant superoxide release by these cells. Technically, sorted cells, here neutrophils, were shown to secrete superoxide after PMA treatment. Similar results were observed after muscle injury upon LPS co-injection, that induces a stronger pro-inflammatory profile in Ly6 $\mathrm{C}^{\text {pos }}$ macrophages (Varga et al., 2016). ROS production is an important feature of macrophages, notably following activation with pathogens (Fang, 2004; Laskin et al., 2011; West et al., 2011), that constitutes a different context from sterile tissue injury. The absence of a high oxidative response in macrophages upon muscle injury, notably in Ly6C ${ }^{\text {pos }}$ macrophages at early time points after injury, was confirmed by gene expression analysis. The mRNA expression of about 30 genes related to oxidative stress did not differ between inflammatory Ly $6 C^{\text {pos }}$ and restorative/Ly6 $C^{\text {neg }}$ macrophage from injured muscle. More broadly, gene profiling analysis of these two populations indicated that following a sterile muscle injury, inflammatory ${\text { Ly } 6 C^{\text {pos }}}$ macrophages exhibit a specific inflammatory profile which is different from the classical M1 (IFN $\gamma$ driven) status and which is strongly different from that of pathogen-challenged macrophages (Varga et al., 2016).

Finally, our in vivo pharmacological approach aimed at targeting ROS production early after injury, with the antioxidant NAC, a molecule commonly used as 


\section{ACCEPTED MANUSCRIPT}

therapeutics in a large number of pathophysiological contexts including skeletal muscle diseases and in exercise and sport performance context (Le Moal et al., 2017; Michailidis et al., 2013). We showed that NAC treatment did not alter macrophage phenotype at early time points after injury, in accordance with the above results indicating the absence or ROS release from macrophages in this context. While the number of necrotic myofibers was not significantly different from that observed in the control muscle, NAC-treated muscles showed a highly heteregenous, somewhat increased level of necrosis 8 days after the injury, deserving further investigation on the phagocytic capacities of macrophages in these conditions. Finally, parameters of myofiber growth and fusion were altered in NAC-treated muscle 28 days after injury, suggesting and impact of anti-oxidant treatment on ROSunrelated properties of restorative macrophages or directly on the myogenesis process. However, the number of satellite cells was unchanged after NAC treatment, suggestive of an impact of NAC on the late stage of myogenesis, that deserves further exploration. Indeed, several pathways involved in myogenesis processes may be regulated by oxidative stress, for instance IGF-I signaling or Akt-mTOR pathways (Le Moal et al., 2017). This is also suggested by a study showing that NAC supplementation after an exercise-induced muscle damage (EIMD) in human blunts the circulating inflammatory response (assessed by indirect measurements in blood) and decreases the EIMD-induced increase in the phosphorylation of a series or proteins involved in myofiber growth (PKB, mTOR, p70S6K, S6, MAPK P38). Consequently, performance of the NAC-treated group was decreased (Michailidis et al., 2013).

Our results appear to be in sharp contrast with what is observed during muscular dystrophies. Indeed, the increase in oxidative stress in muscular dystrophies is a 


\section{ACCEPTED MANUSCRIPT}

well-known process and correlates with the severity of the pathology (Le Moal et al., 2017). Accordingly, anti-oxidant treatments ameliorate the morphological, biochemical, and functional phenotype of the diseased muscle, including a decrease in inflammatory cells (Le Moal et al., 2017). However, the redox status of inflammatory cells, including macrophages, has not been addressed in this pathological context yet. Nevertheless, as the inflammatory status of macrophages is different during skeletal muscle regeneration and during dystrophies (Lemos et al., 2015; Vidal et al., 2008), it is likely that their redox status will also differ significantly between acute and chronic injuries.

In conclusion, this study indicates that, contrary to an immune challenge implicating bacteria or virus, macrophage-derived ROS release is absent or weak after a sterile tissue damage, and does not impact the skeletal muscle regeneration process. Additionally, we report that antioxidant supplementation from the time of injury does not impact macrophage inflammatory status but may conversely be deleterious in the later restorative phase of skeletal muscle regeneration. 


\section{ACKNOWLEDGEMENTS \\ ACCEPTED MANUSCRIPT}

This work was funded by CNRS, INSERM and University of Lyon.

\section{DISCLOSURE STATEMENT}

Authors declare no conflict of interest. 


\section{ACCEPTED MANUSCRIPT}

\section{FIGURES LEGENDS}

Figure 1. ROS and antioxidant measurements in activated macrophages in vitro.

BM-derived macrophages were activated in vitro using different effectors. (A) Detection of superoxide in conditioned medium was performed after $1 \mathrm{~h}$ of incubation with ferricytochrome $c$ solution using spectrophotometry (Optical Density, O.D.). (B) Detection of hydrogen peroxide was performed on conditioned medium with the Amplex Red hydrogen peroxide/peroxidase assay kit. (C) Mitochondrial MnSOD (SOD2) expression by western-blotting. Panel illustrates a representative gel. (D) Cytosolic Cu-ZnSOD (SOD1) expression by western-blotting. Panel illustrates a representative gel. Results are mean +/-SEM. A minimum of 3 independent experiments were performed. ${ }^{*} \mathrm{p}<0.05$ different from untreated (NT) macrophages (A) or IL-10 activated macrophages (C).

Figure 2. Superoxide detection in conditioned medium of macrophages sorted from injured skeletal muscle.

Ly $6 C^{\text {pos }}$ and Ly6C ${ }^{\text {neg }}$ macrophages were sorted from regenerating Tibialis Anterior muscles 2 days after injury with cardiotoxin (A) and with cardiotoxin + LPS (B). On the left, flow cytometry dot plots illustrate a representative experiment showing the 3 sorted populations as neutrophils (black dotted line circle), Ly6C ${ }^{\text {pos }}$ inflammatory macrophages (black plain circle) and Ly6C ${ }^{\text {neg }}$ restorative macrophages (plain gray circle). On the right, detection of superoxide in conditioned medium was performed after $1 \mathrm{~h}$ of incubation with ferricytochrome $c$ solution using spectrophotometry. When indicated PMA treatment $(50 \mathrm{ng} / \mathrm{ml})$ was applied for $60 \mathrm{~min}$. Results are expressed as a percentage of the quantity of superoxide detected in the condition medium of 


\section{ACCEPTED MANUSCRIPT}

control solution (ferricytochrome $\mathrm{c}$ solution, without cells). A minimum of 3 independent experiments were performed. ${ }^{* *} p<0.01,{ }^{* * *} p<0,001$ different from control.

Figure 3. Gene expression profiling of oxidative stress-associated network in macrophages sorted from injured skeletal muscle.

Two days after injury, Ly6C $C^{\text {pos }}$ and $L y 6 C^{\text {neg }}$ macrophages were sorted from regenerating muscle and processed for microarray as in (Varga et al., 2016). Upper panel: heatmap of genes referred as highly expressed in ${\text { Ly } 6 C^{\text {pos }}}$ macrophage subset. Lower panel: heatmap of 30 genes associated with oxidative stress. Results represent the mean of 3 independent experiments.

Figure 4: NAC supplementation effect on early steps of muscle regeneration: impact on macrophages.

Tibialis Anterior muscle was injured and mice were treated or not with NAC for 8 days. (A) Upper panel: Immunofluorescent staining for F4/80 and iNOS or CD206 on regenerating muscle 4 days after injury in control and NAC-treated mice. Arrow represents double-positive cells and arrowheads represent macrophages negative for the inflammatory marker. Bar $=50 \mu \mathrm{m}$. Lower panel: quantification of the number of iNOS $^{\text {pos }}$ and CD206 ${ }^{\text {pos }}$ macrophages. (B) Necrotic/phagocytosed fibers were counted on muscle sections stained with $\mathrm{H} / \mathrm{E}$ at day 8 after injury. Results are mean+/-SEM of a minimum 3 mice.

Figure 5. NAC supplementation effect on late steps of muscle regeneration: impact on myogenesis. 


\section{ACCEPTED MANUSCRIPT}

Tibialis Anterior muscle was injured and mice were treated or not with NAC for 8 days. Muscles were analyzed at day 28. (A) Hematoxylin/Eosin staining of Tibialis Anterior muscle sections of control mice. Bar=50 $\mu \mathrm{m}$. (B) Total body weight, Tibialis Anterior mass and body mass/ Tibialis Anterior muscle/body mass ratio. (C) Mean and distribution of Cross Section Areas. (D) Number of nuclei per myofiber in regenerating muscle. (E) Number of Pax7+ cells per 100 fibers in regenerating muscle. Results are mean $+/-$ SEM of a minimum 3 mice. ${ }^{*} p<0.05,{ }^{* *} p<0.01$, ${ }^{* * *} \mathrm{p}<0.001$ different from control. 


\section{ACCEPTED MANUSCRIPT}

\section{REFERENCES}

Abbas, K., Hardy, M., Poulhes, F., Karoui, H., Tordo, P., Ouari, O., and Peyrot, F. (2014). Detection of superoxide production in stimulated and unstimulated living cells using new cyclic nitrone spin traps. Free Radic Biol Med 71, 281-290.

Arnold, L., Henry, A., Poron, F., Baba-Amer, Y., van Rooijen, N., Plonquet, A., Gherardi, R.K., and Chazaud, B. (2007). Inflammatory monocytes recruited after skeletal muscle injury switch into antiinflammatory macrophages to support myogenesis. The Journal of experimental medicine 204, 1057-1069.

Bernard, A.S., Giroud, C., Ching, H.Y., Meunier, A., Ambike, V., Amatore, C., Collignon, M.G., Lemaitre, F., and Policar, C. (2012). Evaluation of the anti-oxidant properties of a SOD-mimic Mn-complex in activated macrophages. Dalton Trans 41, 6399-6403.

Brune, B., Dehne, N., Grossmann, N., Jung, M., Namgaladze, D., Schmid, T., von Knethen, A., and Weigert, A. (2013). Redox control of inflammation in macrophages. Antioxid Redox Signal 19, 595-637.

Chazaud, B. (2014). Macrophages: supportive cells for tissue repair and regeneration. Immunobiology 219, 172-178.

Fang, F.C. (2004). Antimicrobial reactive oxygen and nitrogen species: concepts and controversies. Nat Rev Microbiol 2, 820-832.

Forman, H.J., and Torres, M. (2001). Redox signaling in macrophages. Mol Aspects Med 22, 189-216.

Holmstrom, K.M., and Finkel, T. (2014). Cellular mechanisms and physiological consequences of redox-dependent signalling. Nat Rev Mol Cell Biol 15, 411-421. 


\section{ACCEPTED MANUSCRIPT}

Laskin, D.L., Sunil, V.R., Gardner, C.R., and Laskin, J.D. (2011). Macrophages and tissue injury: agents of defense or destruction? Annu Rev Pharmacol Toxicol 51, 267-288.

Lawrence, T., and Natoli, G. (2011). Transcriptional regulation of macrophage polarization: enabling diversity with identity. Nat Rev Immunol 11, 750-761.

Le Moal, E., Pialoux, V., Juban, G., Groussard, C., Zouhal, H., Chazaud, B., and Mounier, R. (2017). Redox Control of Skeletal Muscle Regeneration. Antioxid Redox Signal 27, 276-310.

Lemos, D.R., Babaeijandaghi, F., Low, M., Chang, C.K., Lee, S.T., Fiore, D., Zhang, R.H., Natarajan, A., Nedospasov, S.A., and Rossi, F.M. (2015). Nilotinib reduces muscle fibrosis in chronic muscle injury by promoting TNF-mediated apoptosis of fibro/adipogenic progenitors. Nat Med 21, 786-794.

Michailidis, Y., Karagounis, L.G., Terzis, G., Jamurtas, A.Z., Spengos, K., Tsoukas, D., Chatzinikolaou, A., Mandalidis, D., Stefanetti, R.J., Papassotiriou, I., et al. (2013). Thiol-based antioxidant supplementation alters human skeletal muscle signaling and attenuates its inflammatory response and recovery after intense eccentric exercise. Am J Clin Nutr 98, 233-245.

Mounier, R., Theret, M., Arnold, L., Cuvellier, S., Bultot, L., Goransson, O., Sanz, N., Ferry, A., Sakamoto, K., Foretz, M., et al. (2013). AMPKalpha1 Regulates Macrophage Skewing at the Time of Resolution of Inflammation during Skeletal Muscle Regeneration. Cell metabolism 18, 251-264.

Murphy, M.P., Holmgren, A., Larsson, N.G., Halliwell, B., Chang, C.J., Kalyanaraman, B., Rhee, S.G., Thornalley, P.J., Partridge, L., Gems, D., et al. (2011). Unraveling the biological roles of reactive oxygen species. Cell Metab 13, 361-366. 


\section{ACCEPTED MANUSCRIPT}

Murray, P.J., Allen, J.E., Biswas, S.K., Fisher, E.A., Gilroy, D.W., Goerdt, S., Gordon, S., Hamilton, J.A., Ivashkiv, L.B., Lawrence, T., et al. (2014). Macrophage activation and polarization: nomenclature and experimental guidelines. Immunity 41, 14-20.

Nathan, C.F., and Root, R.K. (1977). Hydrogen peroxide release from mouse peritoneal macrophages: dependence on sequential activation and triggering. The Journal of experimental medicine 146, 1648-1662.

Perdiguero, E., Sousa-Victor, P., Ruiz-Bonilla, V., Jardi, M., Caelles, C., Serrano, A.L., and Munoz-Canoves, P. (2011). p38/MKP-1-regulated AKT coordinates macrophage transitions and resolution of inflammation during tissue repair. The Journal of cell biology 195, 307-322.

Rigamonti, E., Touvier, T., Clementi, E., Manfredi, A.A., Brunelli, S., and RovereQuerini, P. (2013). Requirement of Inducible Nitric Oxide Synthase for Skeletal Muscle $\mathrm{Re}=$ after Acute Damage. J Immunol.

Terrill, J.R., Radley-Crabb, H.G., Grounds, M.D., and Arthur, P.G. (2012). NAcetylcysteine treatment of dystrophic $\mathrm{mdx}$ mice results in protein thiol modifications and inhibition of exercise induced myofibre necrosis. Neuromuscul Disord 22, 427434.

Varga, T., Mounier, R., Gogolak, P., Poliska, S., Chazaud, B., and Nagy, L. (2013). Tissue LyC6- macrophages are generated in the absence of circulating LyC6monocytes and Nur77 in a model of muscle regeneration. J Immunol 191, 56955701.

Varga, T., Mounier, R., Horvath, A., Cuvellier, S., Dumont, F., Poliska, S., Ardjoune, H., Juban, G., Nagy, L., and Chazaud, B. (2016). Highly Dynamic Transcriptional Signature of Distinct Macrophage Subsets during Sterile Inflammation, Resolution, and Tissue Repair. J Immunol 196, 4771-4782. 


\section{ACCEPTED MANUSCRIPT}

Vezzoli, M., Castellani, P., Corna, G., Castiglioni, A., Bosurgi, L., Monno, A., Brunelli, S., Manfredi, A.A., Rubartelli, A., and Rovere-Querini, P. (2011). High-mobility group box 1 release and redox regulation accompany regeneration and remodeling of skeletal muscle. Antioxid Redox Signal 15, 2161-2174.

Vidal, B., Serrano, A.L., Tjwa, M., Suelves, M., Ardite, E., De Mori, R., Baeza-Raja, B., Martinez de Lagran, M., Lafuste, P., Ruiz-Bonilla, V., et al. (2008). Fibrinogen drives dystrophic muscle fibrosis via a TGFbeta/alternative macrophage activation pathway. Genes Dev 22, 1747-1752.

Wang, Y., Noel, J.M., Velmurugan, J., Nogala, W., Mirkin, M.V., Lu, C., Guille Collignon, M., Lemaitre, F., and Amatore, C. (2012). Nanoelectrodes for determination of reactive oxygen and nitrogen species inside murine macrophages. Proceedings of the National Academy of Sciences of the United States of America $109,11534-11539$.

West, A.P., Brodsky, I.E., Rahner, C., Woo, D.K., Erdjument-Bromage, H., Tempst, P., Walsh, M.C., Choi, Y., Shadel, G.S., and Ghosh, S. (2011). TLR signalling augments macrophage bactericidal activity through mitochondrial ROS. Nature 472 , 476-480.

Winterbourn, C.C. (2008). Reconciling the chemistry and biology of reactive oxygen species. Nat Chem Biol 4, 278-286. 
A

Superoxide release
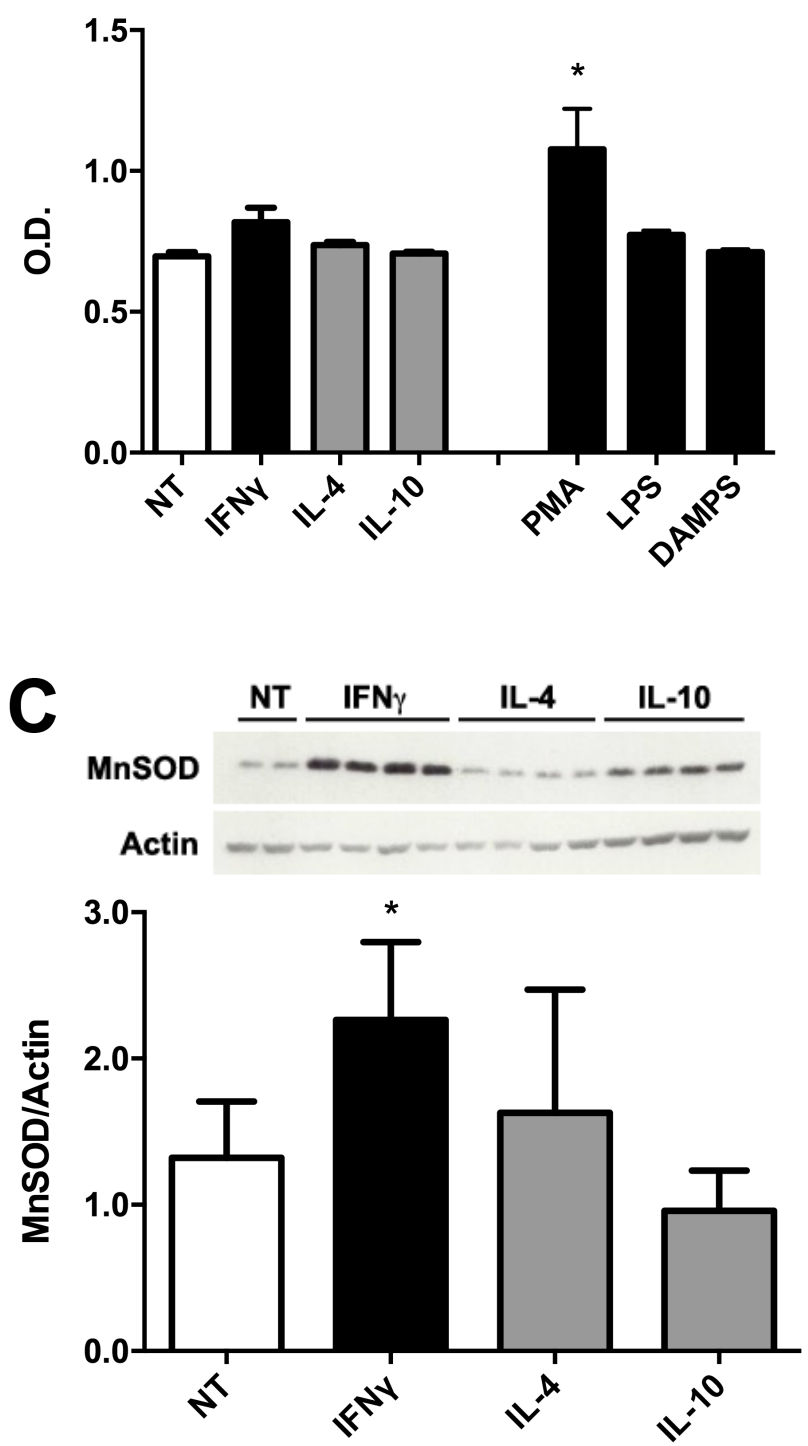

Hydrogen peroxide release
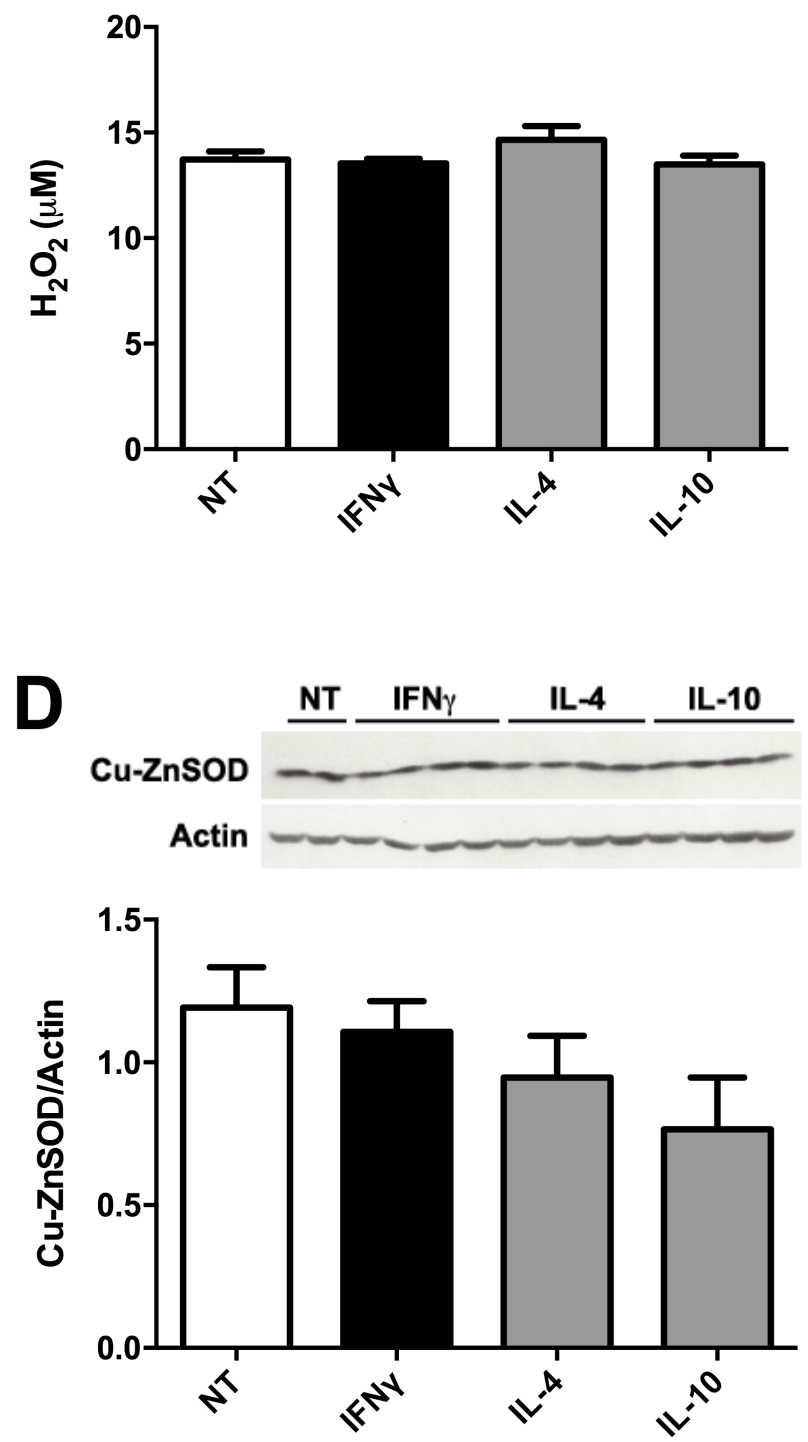

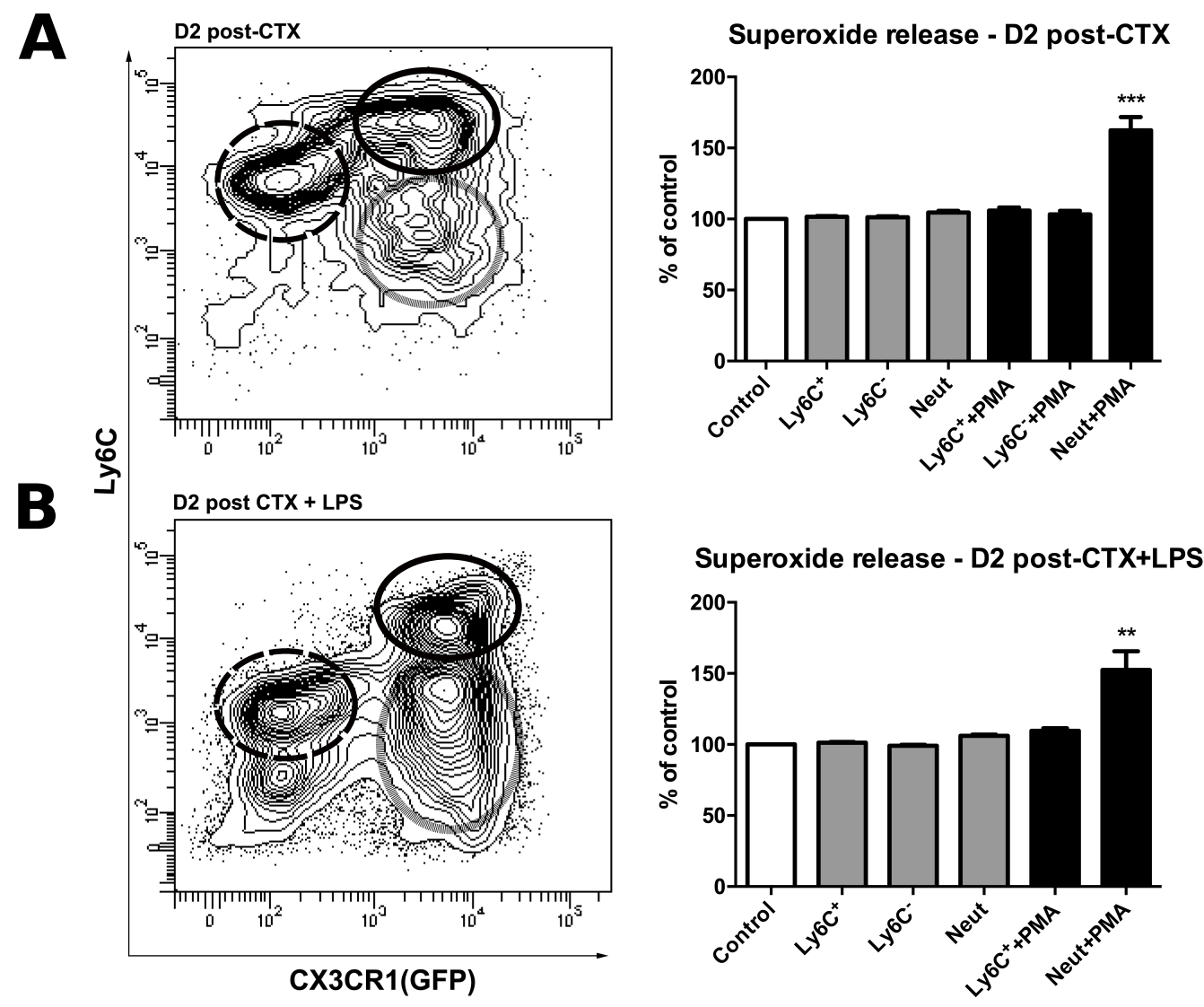


\begin{tabular}{|l|r|r|}
\hline Gene & Ly6C & \multicolumn{1}{|c|}{ Ly6C $^{-}$} \\
\hline Sell & 1.30 & 0.22 \\
\hline Csf1 & 1.12 & 0.07 \\
\hline II6 & 1.28 & 0.40 \\
\hline Ccr2 & 0.00 & -0.25 \\
\hline Ccr1 & 1.16 & 0.60 \\
\hline Ccr5|Ccr2 & 0.18 & 0.06 \\
\hline & \multicolumn{2}{|c|}{} \\
\hline Acox1 & -0.19 & 0.23 \\
\hline Cat & -0.24 & 0.18 \\
\hline Cycs & 0.10 & 0.11 \\
\hline Glrx & 0.42 & 0.02 \\
\hline Glrx2 & 0.30 & 0.45 \\
\hline Glrx3 & 0.06 & 0.46 \\
\hline Glrx5 & 0.34 & 0.57 \\
\hline Gpx1 & -0.05 & 0.06 \\
\hline Gpx3 & -0.46 & -0.06 \\
\hline Gpx4 & -0.02 & 0.32 \\
\hline Grxcr1 & 0.25 & 0.06 \\
\hline Gss & 0.06 & 0.14 \\
\hline Gstp1 & -0.01 & 0.07 \\
\hline Gstp2 & 0.05 & 0.18 \\
\hline Mgst3 & 0.29 & 0.05 \\
\hline Mpv17 & 0.17 & -0.01 \\
\hline Msrb2 & 0.01 & 0.60 \\
\hline Msrb3 & -0.27 & 0.27 \\
\hline ND1 & -0.20 & 0.07 \\
\hline Ndor1 & 0.00 & -0.04 \\
\hline Prdx1 & 0.00 & -0.07 \\
\hline Prdx2 & -0.13 & -0.04 \\
\hline Prdx3 & 0.11 & 0.11 \\
\hline Prdx4 & 0.18 & 0.17 \\
\hline Prdx5 & 0.13 & 0.41 \\
\hline Prdx6 & 0.44 \\
\hline Sod1 & -0.05 \\
\hline Sod2 & 0.04 \\
\hline Txnrd1 & 0.11 \\
\hline Txnrd2 & 0.10 \\
\hline
\end{tabular}


A
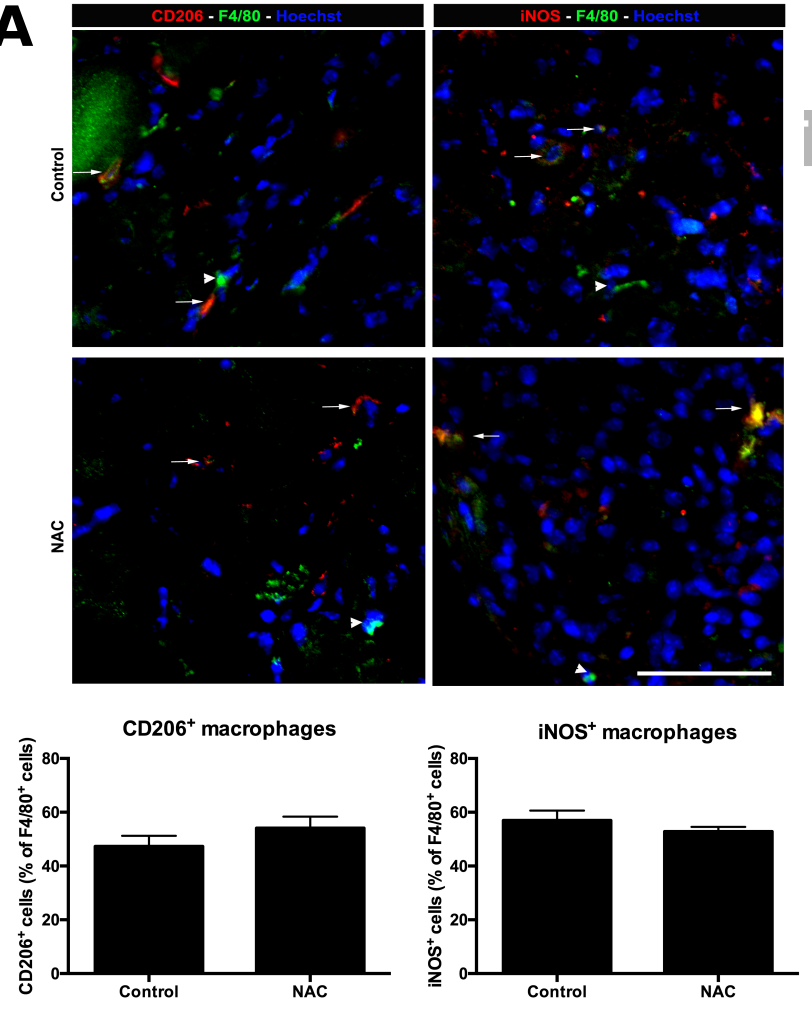

B
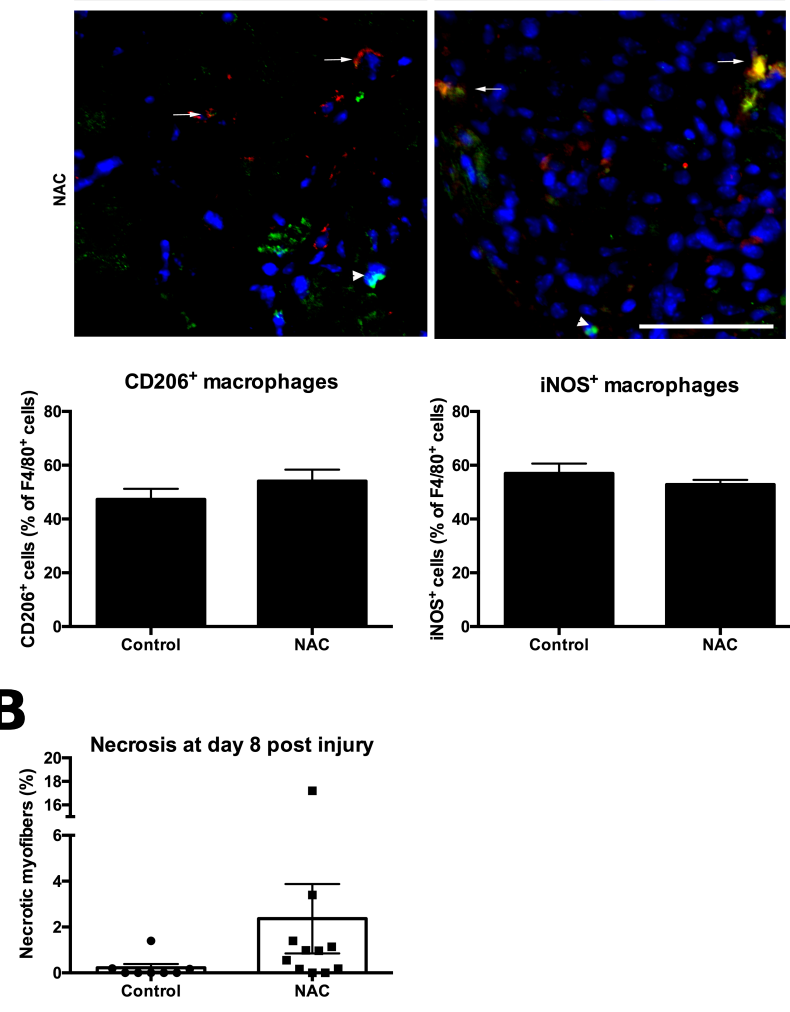
Control

\section{ED MANUSCRIPT}



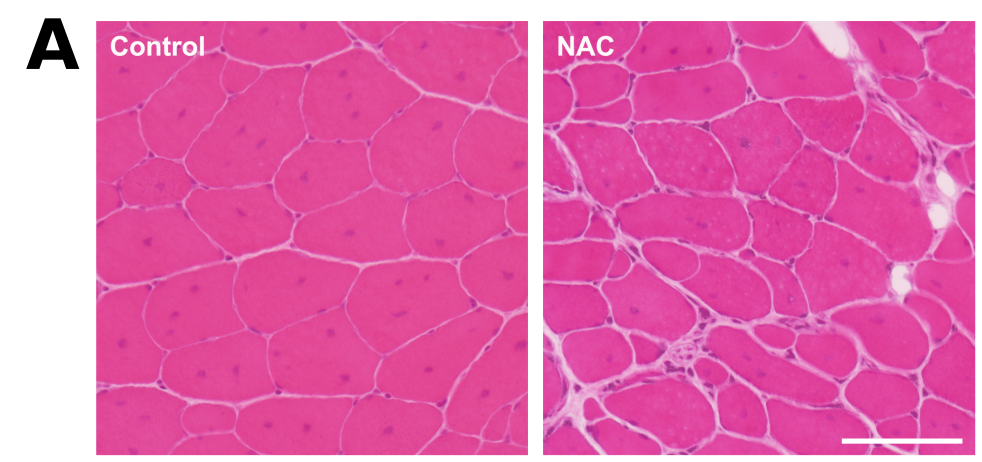

B

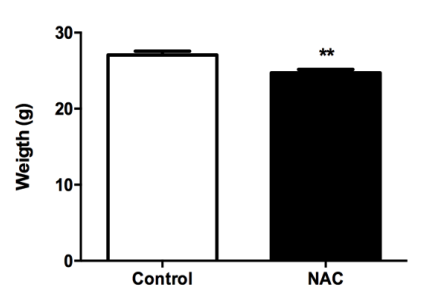

C
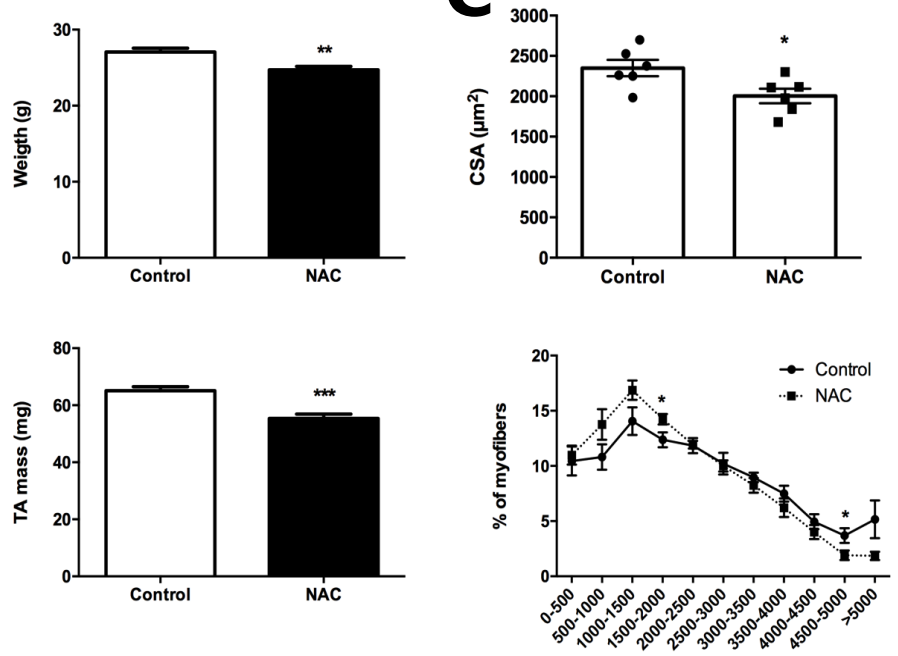

D
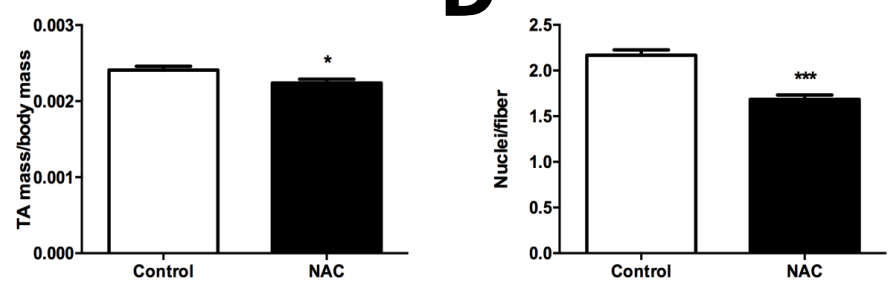

E

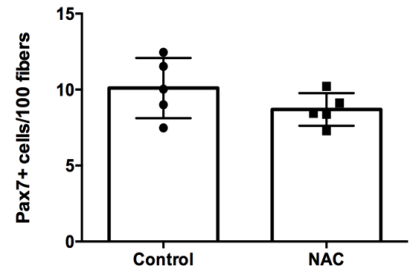




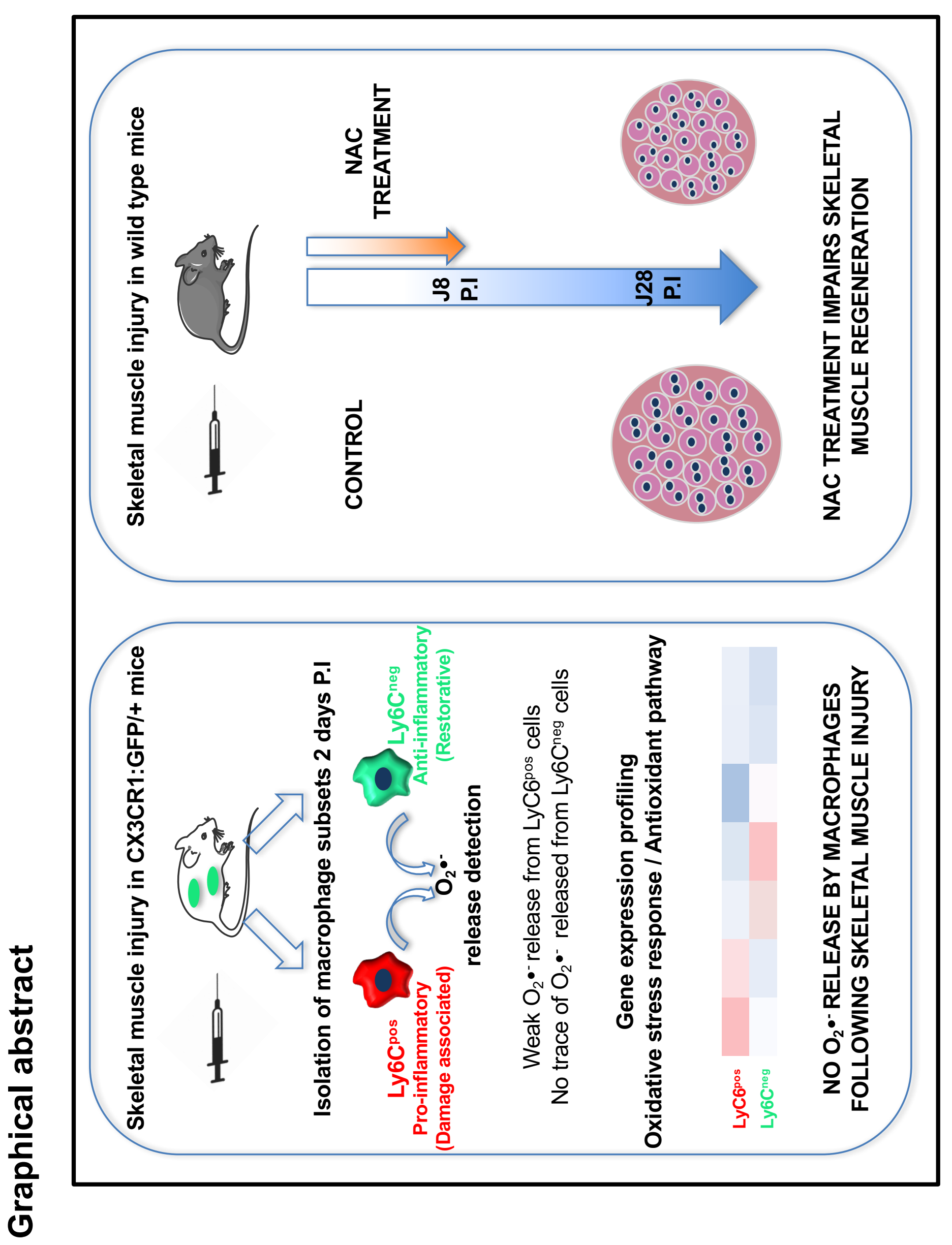

